Nadine J. Kaslow / Susan L. Reviere /

Susan E. Chance / James H. Rogers /

Carrie A. Hatcher / Frances Wasserman / Lisa Smith /

Salley Jessee / Mark E. James / Beth Seelig

\title{
AN EMPIRICAL STUDY OF THE PSYCHODYNAMICS OF SUICIDE
}

This paper presents results from an empirical study of four key psychodynamic concepts (self-directed aggression, object loss, ego functioning disturbance, pathological object relations) of suicidal behavior. The sample consists of hospitalized psychiatric patients following a suicide attempt (attempters: $n=52$ ) and demographically similar hospitalized psychiatric patients with no history of suicidal behavior (controls: $n=47$ ). The study was designed to ascertain whether attempters differed from matched psychiatric control patients on the four psychodynamic constructs hypothesized to be associated with suicide. It was predicted that attempters would manifest higher levels of depression and selftargeted anger, a more significant history of loss, less adaptive defenses, and more primitive object representations. Results strongly supported an object-relational view of suicidal behavior. In addition, support for the loss hypothesis was found in the identification of one specific constellation of losses. Namely, attempters were significantly more likely to report a history of childhood loss combined with a recent loss in adulthood than were their nonattempter counterparts. Limited support was provided for the other two hypotheses in differentiating suicidal from nonsuicidal severely ill psychiatric patients. This unexpected finding is examined and suggestions are made for the refinement and greater specification of psychodynamic theories regarding the etiology of suicidal behavior, with the aim of differentiating individuals prone to such action from those with similar psychopathology and dynamic issues who do not actually attempt suicide. Limitations of the study are discussed and implications of the findings for the theory and treatment of suicidal behavior are offered.

$\mathbf{T}$ he human potential for self-destruction has long been of interest to psychoanalysts. Theories used to explain the motives for suicide, though of considerable clinical utility, have been based largely on clinical psychoanalytic data from a necessarily small number of 
patients. This study is an attempt to obtain, through empirical methods, information about the mental processes accompanying suicide attempts. Specifically, four concepts central to a psychoanalytic understanding of suicide are examined: self-directed aggression; unresolved (pathological) grief in response to object loss; disturbance of ego functioning (e.g., maladaptive and self-sacrificing defenses, impaired reality testing in response to loss and dysphoria); and pathological internal object relations (poorly integrated and hostile introjects, incomplete separation-individuation).

In "Mourning and Melancholia" Freud (1917) stated, "The analysis of melancholia now shows that the ego can kill itself only if, owing to the return of the object cathexis, it can treat itself as an object-if it is able to direct against itself the hostility which relates to an object and which represents the ego's original reaction to objects in the external world" (p. 252). The lost or disappointing object is identified with, and the ego becomes the target of vengeful sadistic wishes. Fenichel (1945), using structural concepts, viewed suicide in depressed individuals as an outcome of the relations between the ego and a sadistic superego. Specifically, the ego either submits to the protecting aspects of the superego for forgiveness and reconciliation, or the ego expresses coercive and rebellious rage against the superego with a wish to destroy it. Played out in a relational context, the deflection of aggression

This study was funded by a grant from the American Psychoanalytic Association Research Fund awarded to Nadine Kaslow (PI) and James Rogers, Mark James, and Sally Jessee (Co-PIs). The authors wish to thank Lawrence B. Inderbitzin for his thoughtful comments on an earlier version of this report. Submitted for publication August 18, 1997.

Nadine J. Kaslow is Associate Professor in the Department of Psychiatry and Behavioral Sciences, Emory University School of Medicine, and Chief Psychologist, Grady Health System. Susan L. Reviere is Assistant Professor in the Department of Psychiatry and Behavioral Sciences, Emory University School of Medicine. Susan E. Chance is a Psychology Intern in the Department of Psychiatry and Behavioral Sciences, Emory University School of Medicine, and a graduate student at Georgia State University. James H. Rogers is a Supervising Psychologist, Georgia State University. Carrie A. Hatcher is a graduate student in clinical psychology at the University of Michigan. Frances Wasserman is a nurse practitioner in Punta Gorda, Florida. Lisa Smith is a psychiatrist in the Forensic Service at Georgia Regional Hospital. Salley Jessee is a Training and Supervising Analyst, Emory University Psychoanalytic Institute, and an adjunct faculty member in the Department of Psychiatry and Behavioral Sciences, Emory University School of Medicine. Mark E. James is a candidate at the Emory University Psychoanalytic Institute and an adjunct faculty member in the Department of Psychiatry and Behavioral Sciences, Emory University School of Medicine. Beth Seelig is Associate Professor in the Department of Psychiatry and Behavioral Sciences, Emory University School of Medicine, and a Training and Supervising Analyst, Emory University Psychoanalytic Institute. 
toward the self serves to restore a threatened relationship via repentant self-punishment (Rado 1951) and represents an act of retaliatory abandonment against objects who have been lost or have threatened to leave (Haider 1968). According to Kohut (1977), aggressive responses emerge as a byproduct of the breakdown of self-cohesion resulting from narcissistic injury. Suicide then reflects a response to feelings of narcissistic rage, shame, or other forms of aversive self-awareness (Baumeister 1990).

Alternative psychodynamic formulations emphasize the affiliative and libidinal vicissitudes of object loss related to depression and suicide as opposed to, or in addition to, the expression of aggression, which may then be viewed as secondary. From this perspective, suicide may represent a fantasied narcissistic reunion (re-fusion) with a lost love object (Fenichel 1945; Hendin 1991), serving to undo the loss or separation. In Asch's words (1980), "much of the meaning of the usual suicidal act can be understood once we recognize that there is frequently a double aim of first cleansing the self, and then uniting (actually reuniting) with an omnipotent love object" (p. 52). Research findings support the clinical observation that individuals who experience early losses, painful separations, and unstable familial relationships constitute a high-risk group for suicidal behavior (see, e.g., Cross and Hirschfield 1986; Wasserman 1988).

Theories concerned with ego functioning describe the use of particular constellations of defense mechanisms by suicidal individuals. These include aggression turned against the self, primitive denial, splitting, primitive idealization, introjection, regression, identification with the aggressor, and repression (Apter et al. 1989; Freud 1917; Kernberg 1975; Scholz 1973). Further, impaired reality testing may occur in the context of regression associated with dysphoria and anger, often in situations of perceived abandonment or loss of self-esteem (Marcus 1988).

Object relations theory focuses on suicide as an attempt, in fantasy, to destroy bad internal objects - introjects (Kernberg 1975; Klein 1934) - or unwanted aspects of the self. For example, Winnicott (1958, 1960) depicted suicide as involving a fantasy of destroying bad aspects of the self with the remainder of the self surviving, or as a destruction of the entire self when the true self is threatened with exploitation or annihilation. In a related vein, object relations theorists also report that suicidal individuals often evidence poorly integrated hostile introjects 
and few positive soothing introjects (Maltsberger and Buie 1980). They may project and enact interpersonally these pathological internal object relations (Asch 1980). Preliminary data based on a subsample of participants from the current study provided some support for these object-relational constructs. Specifically, higher levels of suicidal intent were associated with less differentiated self- and object representations and a lower level of emotional investment in relationships (Chance et al. 1996).

This paper empirically examines these four psychodynamic concepts (self-directed aggression, object loss, ego functioning disturbance, and pathological object relations) with regard to two groups of demographically similar nonschizophrenic psychiatric inpatients: those hospitalized following a suicide attempt and those with no suicide attempt who were hospitalized for other reasons. It was predicted that the former would manifest higher levels of depression and self-targeted anger, more losses (early and recent), less adaptive defenses, and more primitive object representations.

\section{METHOD}

\section{Subjects}

The sample consisted of 99 psychiatric inpatients, 61 females and 38 males, ages 18 to 71 . The majority of the participants (65.7\%) were African American, and most were high school graduates. Most of those in the sample were of low socioeconomic status.

The patients were hospitalized at a university-affiliated public hospital following a suicide attempt $(n=52)$ or for other psychiatric difficulties necessitating hospitalization $(n=47)$. Patients were excluded if they met DSM-III-R diagnostic criteria for schizophrenia spectrum disorders, bipolar disorder, organic conditions, or mental retardation, or if they had a life-threatening medical illness. In the suicide attempt group, patients reported the following methods of attempt: overdose $(63.4 \%)$, gunshot (11.5\%), significant cutting (7.7\%), and other (ingestion of toxic substances, hanging, burning, jumping) (17.3\%). Nonattempters were admitted for brief psychotic episodes, depressive and anxiety disorders, substance abuse, and impulsive acting out. Nonattempters were excluded from the sample if they had any prior history of suicidal behavior. There were no significant differences between attempters and controls on key demographic variables (e.g., age, sex, race). Table 1 presents demographic data for the entire sample. 
TABLE 1

\section{SAMPLE DEMOGRAPHICS}

Age

Mean: 33

Range: $17-70$

Education (\# years)

Mean: 12

Range: 5-18

Gender

female

$57 \%$

male

$3 \%$

Ethnic Group

African American

$61 \%$

Caucasian

$31 \%$

Other

$8 \%$

Previous

Hospitalizations

no

$38 \%$

yes

$49 \%$

Residence

alone

$15 \%$

family/friends

$73 \%$

group home

$1 \%$

homeless

$4 \%$

Marital Status

married

$20 \%$

divorced

$23 \%$

widowed

$5 \%$

single

$45 \%$

Employment

employed

$31 \%$

unemployed

$29 \%$

unemployed with

$33 \%$ assistance

Percentages totaling less than $100 \%$ reflect missing data.

\section{Procedure}

Attempters were recruited for the study within one week of admission to the psychiatric unit and up to two weeks after their suicide attempt. Control subjects were invited to participate within one week of admission. Patients who agreed to take part in this study provided written informed consent. To enhance compliance, participants received financial remuneration for their involvement. 
Patients completed a battery of self-report questionnaires with adequate validity and reliability, a structured diagnostic interview with a trained clinician, a psychodiagnostic assessment with a supervised graduate student in clinical psychology, and a videotaped psychoanalytic interview conducted by a psychoanalyst or analytic candidate. The projective measures were scored by advanced doctoral-level students in clinical psychology and doctoral-level clinical psychologists trained in personality assessment and psychodynamic theory. Interrater reliability was obtained on the scoring of each projective measure (e.g., Rorschach, Thematic Apperception Test, Object Relations Inventory), and satisfactory interrater reliability was obtained for each measure and coding schema. This paper focuses on the self-report, diagnostic interview, and psychodiagnostic assessment data only. A preliminary overview of the psychoanalytic interview data from participants in this study is presented in Jessee et al. (1995/1996).

\section{Measures}

Psychological symptoms. For the suicide attempter subsample, the severity of suicidal intent at the time of the attempt was ascertained via the Suicide Intent Scale (Beck, Schuyler, and Herman 1974). This measure has been found to differentiate between suicide completers and attempters. The scale was not administered to participants in the control group, as they had made no attempt for which intent could be determined. Instead, for the control group the Scale for Suicide Ideation (Beck, Kovacs, and Weissman 1979) was used to ascertain the degree to which they think about killing themselves. This scale has been efficacious in ascertaining risk of suicide and other selfdestructive behavior.

DSM-III-R Axis I and Axis II diagnoses were obtained via the Structured Clinical Interview for DSM-III-R Patient Edition (SCID-P) and the Structured Clinical Interview for DSM-III-R Personality Disorders (SCID-II), respectively (Spitzer et al. 1990a,b). The SCID-P, the most widely used semistructured diagnostic interview, provides information regarding the major Axis I diagnostic categories. The SCID-II, viewed as the optimal instrument for assessing presence or absence of a DSM-compatible personality disorder, has as its primary advantages the speed of delivery and the fact that it complements the Axis I instrument. For purposes of data analysis, SCID-P and SCID-II data were grouped into the following categories: depressive disorders, 
anxiety disorders, substance abuse/dependence, adjustment disorders, other Axis I diagnoses, and Cluster $\mathrm{A}, \mathrm{B}$, and $\mathrm{C}$ personality disorders. Both the SCID-P and the SCID-II provide descriptive diagnoses, without reference to psychodynamics, level of personality organization, or possible unconscious issues and affects.

The Beck Depression Inventory (BDI) (Beck et al. 1961), a selfreport scale, assesses the cognitive, affective, motivational, and neurovegetative symptoms of depression (Beck, Steer, and Garbin 1988).

Presence and severity of depression and suicide risk were assessed via the Depression and Suicide Constellations of the Rorschach, scored in accordance with Exner's Comprehensive System (1993). That system has become standard for coding Rorschach responses with regard to reality testing and thought disorder, affects and affect regulation, availability of coping resources, and interpersonal styles. However, the coding schema does not assess underlying dynamics, and no fantasy content is interpreted.

Self-directed aggression. A modified version of the Self-Targeted Anger (STA) scale (Knopf et al.1990) was the primary instrument used to test the theory that suicidal acts reflect self-directed aggression. The scale was modified using a computer-based literacy program to enhance the patient's understanding of the questions. This scale discriminates between self- and externally targeted anger. The scale is primarily a state measure, as the items tap conscious cognitive evaluations of specific ways in which subjects experience and express their aggressive impulses. This scale does not attempt to measure unconscious aggression.

A second measure of aggression was the frequency of aggression responses on the Rorschach (Exner 1993). High numbers of aggression responses are indicative of aggressive impulses and the perception of aggression and hostility in others. Another item used to tap aggressive impulses was a question on the background information form about presence or absence of homicidal ideation.

Feelings of shame and guilt were evaluated via a modified version of the Shame-Guilt Scale (Gioella 1979), which includes a list of adjectives associated with shame or guilt. Again, these modifications were done in accord with a computer-based literacy program so that the words were more consistent with the literacy level of the patients served at the hospital. 
Loss. To examine the loss hypothesis, demographic data regarding history of early loss, nonrecent adult loss, and recent adult loss were obtained.

Ego functioning. To assess ego functioning, the Bond Defense Style Questionnaire (BDSQ) (Bond 1984/1986) and Rorschach ego structure measures were used. The BDSQ is a self-report measure of conscious derivatives of defenses. The BDSQ, developed in accord with Vaillant's hierarchy of defenses (Vaillant, Bond, and Vaillant 1986), examines four categories of defenses: maladaptive (immature defenses such as withdrawal, regression, acting out, inhibition, passive aggression, projection), image distorting (omnipotence, splitting, primitive idealization), self-sacrificing (reaction formation, pseudoaltruism), and adaptive (suppression, sublimation, humor) (see also Flannery and Perry 1990).

Rorschach ego structure measures, based on Exner's Comprehensive System, were the Coping Deficit Index (CDI) and the Schizophrenia Index (SCZI). High scores on the CDI are indicative of limited adaptive ego functions for contending with stress and impoverished interpersonal relations. Data reveal that the CDI is an adequate measure of helplessness (Exner 1993). High scores on the SCZI are associated with markers of compromised ego functioning such as disordered thinking, impaired reality testing, boundary confusion, and difficulties with the regulation of distressing affects and cognitions.

Object representations. Internalized object representations and interpersonal dynamics were measured by responses to the Rorschach, the Object Relations Inventory (ORI), and the Thematic Apperception Test (TAT). The Rorschach test was administered and scored according to Exner's guidelines (1990). The score relevant to object relations was the Hypervigilance Index (HVI) of the Rorschach, which measures fear of intimacy with others due to a perception that other people cannot be trusted (Exner 1993).

Rorschach responses also were scored in accord with the revised Rorschach separation-individuation scale (Diamond et al. 1990), an expansion of Coonerty's separation-individuation scale (1986). This scale assesses preseparation, individuation, and separationindividuation themes (autistic/symbiotic phase, early differentiation, narcissism/practicing, rapprochement/separation, object constancy, intersubjectivity). During long-term psychoanalytic inpatient treatment, 
this scoring system has been shown to be sensitive to patients' improvements (Diamond et al. 1990).

The ORI assesses the level and quality of object relations through descriptions of self, mother, father, and significant other. The ORI was scored using the self-other differentiation scale (Diamond et al. 1990), a ten-point rating scale based on the work of Mahler and colleagues (Mahler, Pine, and Bergman 1975) and Stern (1985). This scale measures self-other relationships at various levels of separation-individuation. For the analyses in this study, the measure used to determine patients' optimal level of object relations was the highest developmental phase scored on any of their self- or object representations.

A preset series of eight TAT cards was administered and coded on four dimensions: complexity of representations of people, affect tone of relationship paradigms, capacity for emotional investment in relationships, and understanding of social causality (Westen et al. 1990).

\section{RESULTS}

The following is a description of the diagnoses of the individuals in the sample based on their responses to the semistructured diagnostic interview (SCID-P, SCID-II). Data are presented for the total sample, as there were no significant between-group differences in terms of diagnosis. Patients were classified into the following categories based on their primary DSM-III-R Axis I diagnoses: depressive disorders (49\%), anxiety disorders (6\%), substance use disorders (25.6\%), adjustment disorders (13.1\%), and other (6\%). Based on their Axis II symptomatology and diagnoses, $2 \%$ met criteria for a Cluster A personality disorder (paranoid, schizoid, schizotypal), 63.6\% met criteria for a Cluster B personality disorder (antisocial, borderline, histrionic, narcissistic), $7 \%$ met criteria for a Cluster $\mathrm{C}$ personality disorder (avoidant, dependent, obsessive compulsive), $11 \%$ received the diagnosis of Personality Disorder NOS (which also places them in the Cluster C category), and $16.2 \%$ met no SCID-P criteria for an Axis II disorder. Findings from a subsample of patients (20 attempters, 20 controls) for whom psychodynamic interviews were conducted by analysts or analytic candidates suggest that a majority of the participants were organized on a low borderline level (Jessee et al. 1995/1996).

Consistent with the fact that $64.6 \%$ of patients met criteria for a primary or secondary depressive disorder, patients in the entire sample 
self-reported high levels of depressive symptoms on the BDI (Mean score $=22.4$, Standard Deviation $=12.1$, with a BDI score of $\geq 20$ indicating clinical depression. There were no between-group differences on BDI scores $(p>.05)$. Consistent with the high rates of substance abuse/dependence as a primary or secondary diagnosis $(56.5 \%)$, as well as the literature documenting an association between substance use and suicidal behavior (Beautrais et al. 1996), it is not surprising that $76.9 \%$ of patients were using alcohol or drugs at the time of their suicide attempt.

Table 2 presents the means and standard deviations for all of the measures separately for suicide attempters and control subjects. These data are also provided for the entire sample. Presence or absence of between-group differences are noted in terms of $p$ values.

\section{Attempters versus Nonattempters}

Statistical analyses comparing group means on the constructs of interest were conducted to test the validity of the four psychodynamic explanations of suicidal behavior examined in this study when the dependent variables were continuous (multivariate analyses of variance, or MANOVAs). For these analyses, the two groups (attempters, controls) were compared in four different analyses, each combining the variables pertaining to a specific construct (anger, loss, ego functioning, object relations) to obtain an overall measure of group differences across variables for that construct. When these MANOVAs yielded significant between-group differences, additional analyses (one-way analyses of variance, or ANOVAs; logistic regression analyses) were conducted to determine the nature of these differences measure by measure.

In examining the self-directed aggression hypothesis, the initial analysis (MANOVA) was performed with the STA scale (self-targeted and externally targeted subscales), the Aggression score from the Rorschach, and the Shame-Guilt Scale. No between-group differences were found for the MANOVA testing the self-directed aggression hypothesis $(p>.05)$, and therefore no subsequent analyses were conducted. Since homicidal ideation is a dichotomous variable that falls within the rubric of the anger hypothesis, an analysis for dichotomous variables (logistic regression) was performed. Results from this analysis revealed that the attempters acknowledged significantly more homicidal ideation than did the controls (Wald $=15.9, p<.001$, 
Table 2: Means and Standard Deviations for Attempters, Controls, AND TOtal SAMPLE

\begin{tabular}{lllll}
\hline \multirow{2}{*}{ Measure } & \multicolumn{4}{c}{ Group Status } \\
& Suicide & Control & P & Total \\
& Attempters & Subjects & Value & Sample \\
\hline Beck Depression (BDI) & & & &
\end{tabular}

Beck Depression (BDI)

$\begin{array}{llrrr}M & 23.10 & 21.60 & & 22.35 \\ \text { SD } & 12.88 & 11.41 & .56 & 12.13\end{array}$

Self-Targeted Anger (STA)

$\begin{array}{lrrrr}M & 10.66 & 10.34 & & 10.50 \\ \text { SD } & 4.26 & 4.63 & .72 & 4.44\end{array}$

Shame-Guilt Scale

$\begin{array}{lrrrc}M & 113.44 & 115.30 & & 114.4 \\ \text { SD } & 51.30 & 27.73 & .84 & 39.51\end{array}$

Bond Defense (BDSQ) Adaptive

$\begin{array}{lrrrr}M & 35.54 & 34.73 & & 35.15 \\ \text { SD } & 9.55 & 8.99 & .99 & 9.25\end{array}$

Bond Defense (BDSQ) Image Distorting

$\begin{array}{lllll}M & 69.33 & 67.22 & & 68.31 \\ \text { SD } & 19.09 & 19.42 & .94 & 19.17\end{array}$

Bond Defense (BDSQ) Maladaptive

$\begin{array}{lrrrr}M & 161.48 & 155.67 & & 158.67 \\ \text { SD } & 42.93 & 38.54 & .89 & 40.75\end{array}$

Bond Defense (BDSQ)

Self-Sacrificing

$\begin{array}{lllll}M & 42.35 & 39.56 & & 41.00 \\ \text { SD } & 10.66 & 11.06 & .46 & 10.89\end{array}$

Object Relations (ORI)

$\begin{array}{lllll}M & 4.36 & 4.71 & & 4.53 \\ \text { SD } & 0.73 & 0.72 & .03 & 0.74\end{array}$

TAT Complex Representations

M $\quad 2.41$

$2.78 \quad 01 \quad 2.60$

SD $\quad 0.54$

0.67

0.62

TAT Affect Tone

$\begin{array}{lllll}M & 2.34 & 2.57 & & 2.50 \\ \text { SD } & 0.42 & 0.39 & .02 & 0.42\end{array}$

TAT Emotional Investment

$\begin{array}{lllll}M & 2.17 & 2.39 & & 2.28 \\ \text { SD } & 0.47 & 0.46 & .44 & 0.48\end{array}$

TAT Social Causality

$\begin{array}{ll}M & 2.34 \\ \text { SD } & 0.55\end{array}$

2.39

.01 
beta $\left.=1.88, \mathrm{R}^{2}=.11\right)$. Attempters were 6.6 times more likely than controls to report homicidal ideation during the past year.

In assessing the loss hypothesis, the two groups were compared in terms of presence or absence of any significant childhood loss, adult loss, recent loss, or lifetime loss. Separate analyses (logistic analyses) for childhood loss and lifetime loss indicated no significant betweengroup differences $(p>.05)$. However, when early childhood and recent adult losses were combined, a significant between-group difference emerged, with suicide attempters being four times more likely to report this combination of losses than their nonattempter counterparts $(p<.05)$. It also should be noted that very high levels of childhood, adulthood, and recent loss were reported by all study participants. Specifically, $45 \%$ of the sample reported significant childhood loss, $31 \%$ noted significant nonrecent losses during adulthood, and $25 \%$ acknowledged recent adult loss. These rates are considerably higher than those reported in the general population.

To test the hypothesis that there would be differences in the ego functioning of suicide attempters and that of control subjects, a MANOVA was conducted that compared the two groups of participants on the following variables: BDSQ, CDI index of the Rorschach, and SCZI index of the Rorschach. Given the lack of between-group differences on the MANOVA $(p>.05)$, no additional analyses for ego functioning variables were undertaken.

Finally, a MANOVA was conducted using group status as the independent variable and measures of object relations as the dependent variables (4 TAT subscales, overall ORI separation-individuation scores, highest category rated according to the Rorschach separationindividuation score). Significant between-group differences emerged on the MANOVA $\left(\mathrm{F}_{(1,59)}=3.9, p<.01\right)$, with attempters evidencing object relations more impaired than those of nonattempters. This overall difference in level of object relations was attributable to between-group differences on the majority of the dependent variables, including TAT affect tone $\left(\mathrm{F}_{(1,59)}=4.3, p<.05\right)$, TAT emotional investment $\left(\mathrm{F}_{(1,59)}=7.5, p<.01\right)$, TAT complexity of relationships $\left(\mathrm{F}_{(1,59)}=5.5, p<.05\right)$, and the highest level of separation-individuation according to Rorschach responses $\left(\mathrm{F}_{(1,59)}=7.5, p<.01\right)$. Specifically, compared to control subjects, attempters view relationships more negatively, are less invested in relationships, hold less complex views of others, and have achieved a lower overall level of separation- 
individuation. In addition, there was a trend for the control subjects to exhibit more mature and well-differentiated levels of self- and object representations on the ORI $(p<.10)$.

\section{DISCUSSION}

Results from this investigation show that suicide attempters as compared to demographically similar and DSM-III-R diagnostically comparable psychiatric control subjects with no previous history of suicide attempts had more impairment in object relations. Specifically, they appeared to view relationships in a more negative manner and to have less emotional investment in them. In addition, attempters held less complex views of relationships, and their self- and object representations indicated lower levels of separation-individuation, consistent with severe borderline intrapsychic structure. The finding that attempters were far more likely to have a history of childhood loss combined with a recent adult loss provides support for the theory that object loss is important in the etiology of suicidal behavior. The loss concept is thereby refined, as both the attempter and the control groups had a much higher incidence of loss than would be expected in the general population. Further, a limited amount of support was obtained for the self-directed aggression hypothesis. Specifically, although attempters did not acknowledge more self-targeted or externally targeted anger than did controls, or more aggression responses on the Rorschach, they did report significantly more homicidal ideation. Finally, no empirical support was found in this study for the ego functioning hypothesis.

The findings from this empirical examination provide strong support for an object-relational understanding of suicidal behavior. Compared to attempters, controls revealed more complex representations of people, indicating that they can differentiate themselves more clearly from others, are more able to perceive both themselves and others as having stable, enduring, and multidimensional dispositions, and have a greater capacity to view themselves and others as psychological beings with complex motives and subjective experiences. In addition, attempters were more likely than controls to expect profound malevolence or overwhelming pain in interpersonal relations. This is consistent with an inner world, characterized by a predominance of more primitive, aggressively charged part-object representations, in which the major defenses employed include splitting and primitive 
forms of projection, especially projective identification. Such a picture is typical of patients with borderline intrapsychic structure, as described by Kernberg $(1975,1984)$. Thus, it is not surprising that these individuals have greater difficulty experiencing interpersonal interactions as meaningful and relationships as committed, and are at greater risk for suicidal behavior. Findings from these quantitative data are supported by the interview data reported for this sample by Jessee et al. $(1995 / 1996)$. They found that attempters were more likely than nonattempters to report that an interpersonal conflict precipitated their hospitalization. It should be noted that these findings may suggest that attempters suffer from more severe psychopathology than do controls, but not from a disturbance of object relations specific to them as a group. To determine whether this is so, future investigations should control for level of disturbance across the groups and/or include a third sample (e.g., outpatients, nonpsychiatric patients) to enable the disentangling of what in the findings might be attributable to level of disturbance from what is specific to suicide attempters.

The data gleaned from this study that are related to the loss hypothesis are interesting and suggest that further exploration of the qualitative nature of loss is very important. The finding that a combination of early and recent loss is likely to be found in attempters suggests that this may be a significant risk factor to be addressed in suicide prevention. Further work should be done to determine which indices of loss would be useful. The measure of loss in this study was based simply on the presence or absence of a significant interpersonal loss at various developmental stages. This information does not address presence or absence of a desire to reunite with the lost object, which is psychodynamically central to the loss hypothesis. Future examination of the videotaped and transcribed interview data, combined with a reexamination of the Rorschach responses using content analysis, will be used to ascertain the salience of reunion fantasies in attempters as compared to controls.

As noted above, this study provides very little direct support for the self-directed aggression hypothesis. On the quantitative measures, no between-group differences were revealed in terms of levels of selfdirected anger, despite the fact that on psychoanalytic interview unconscious rage toward an abandoning object and a desire to gain control, power, and importance were the most evident motivators of selfharm (Jessee et al. 1995/1996). The lack of between-group differences 
on levels of self-targeted anger may be attributable to the fact that the scale used to measure self-directed aggression assesses only one small component of the individual's conscious and cognitive awareness of self-directed aggressive impulses. The scale has no mechanism by which to measure unconscious impulses. Even when one considers only conscious forms of self-directed aggression, there are many forms, such as continual self-criticism and minimization of one's accomplishments, that are more subtle, yet potentially more psychologically devastating, than the content tapped in the Self-Targeted Anger scale. This suggests the importance of developing a scale that includes other forms of selfdirected aggression, both conscious and unconscious. Most available measures have been developed to assess conscious motivation, affect, and cognition. This study employed some of the measures generally accepted by nonpsychoanalytic researchers in an effort to obtain results comparable with those of other studies. The lack of findings on this measure may also be a function of the fact that the Self-Targeted Anger Scale is a relatively new measure for which there is as yet a paucity of psychometric data.

The finding of no group differences on externally targeted anger, but more homicidal ideation in attempters than in controls, is of note. These overtly contradictory findings may reflect in part the fact that the measure of externally targeted anger assesses conscious awareness of angry impulses rather than unconscious aggressive impulses. In addition, it is possible for an individual to have conscious homicidal ideation without conscious awareness of anger toward the target of the ideation. This higher level of homicidal ideation is consistent with the formulation that homicidal rage, when retroflexed, can result in overtly suicidal behavior. The psychoanalytic interview data gathered on a subsample of the study participants and reported by Jessee et. al. $(1995 / 1996)$ showed that "suicide attempters were four times more likely (when compared to any other motivation) to evince murderous rage towards an abandoning other as the motivation for their attempt" (p. 294). The psychodynamic meaning of the suicidal actions that were evaluated in this study of the videotaped psychoanalytic interview data was assessed in part by an evaluation of the participants' unconscious, as well as conscious, motivations. Currently available measures (with the exception of projective tests) measure conscious fantasy and affects. It is important to develop scales that can empirically measure unconscious fantasy and affects. 
One possible explanation for the dearth of empirical support garnered in this study for the ego functioning hypothesis relates to the literacy level required to read and comprehend fully the measure of ego functioning (BDSQ) used. Due to low levels of reported functional literacy in many of the individuals who receive services at this hospital (Williams et al. 1995), the BDSQ may not be appropriate for this patient population. Whereas some of the other measures (e.g., STA, ShameGuilt Scale) were modified to be more appropriate to the literacy level of the patients, this was not done with the BDSQ. Of course, the problem with modifying measures is that it raises questions about the validity of the scale, unless thorough psychometric analyses of the modified scales are conducted. Another possibility that must be considered is that ego strength and the level and nature of defenses do not differentiate psychiatric patients requiring hospitalization who attempt suicide and those who do not.

A number of alternative explanations should be considered and examined empirically before definite conclusions are drawn regarding the validity of the four psychodynamic hypotheses regarding the etiology of suicidal behavior that are examined here. First, with the focus of this investigation being on quantitative measures, it may be that insufficient attention was paid to unconscious factors in fact more central to the hypotheses being tested. Future studies, as well as further examinations of the data from this study, should focus in greater depth on unconscious processes revealed in the projective measures and through the interview data.

Second, the four hypotheses being tested are at different levels of specificity (i.e., the self-directed aggression hypothesis is much more specific than the pathological object relations and ego functioning disturbance hypotheses). Future research in this area needs to test hypotheses at similar levels of specificity.

Third, all four of the models being tested were developed primarily as explanations for suicide completions. Although there may be some similarities in the dynamics underlying suicide attempts and completions, there may also be significant differences. With a larger sample, it might be possible to separate out attempters with a very high probability of completion from those with a very low probability. As most suicide attempts with a very high probability of lethality are successful, it would require a very large population of suicide attempters to obtain these data. 
Fourth, it also is possible that the limited between-group differences on two of the four psychodynamic constructs may be contributed to by the fact that the patients in the current study, regardless of group status, shared a great deal of underlying character pathology and depressive symptoms, despite their differences in suicidal behavior. Therefore, virtually all of the participants in this project evidenced severe psychopathology, and the assessments conducted in this investigation may not have been sensitive enough to detect between-group differences on two of the psychodynamic constructs. Many, if not all, of the constructs hypothesized to differentiate between suicide attempters and nonattempters are also the basis for a psychodynamic explanation of depression and/or character pathology. Thus, these models may be more specific to depression or borderline pathology than to suicidal behavior. The proponents of most of these models view suicidal behavior as a symptom of an underlying illness and thus may not support the hypotheses proposed in this study.

Finally, it may be the case that a number of the commonly espoused psychodynamic explanations are incorrect and/or insufficient to explain the complexities underlying suicidal behavior. Before definitive conclusions can be drawn regarding the empirically based validity of the major psychodynamic constructs of suicidal behavior, there needs to be further exploration of possible psychodynamic explanations of suicidal behavior. These psychodynamically informed research endeavors must take into account the aforementioned concerns related to assessment, devices used, population studied, and similarities in diagnosis across groups studied.

Clinical implications of this study include the great importance of assessing level of object relations, nature of loss, and presence of homicidal ideation in patients as part of an assessment of suicide risk. Clinical interventions with acutely suicidal individuals should target enhancing their interpersonal skills and bolstering their support networks. Once the acute suicidal crisis has abated, dynamically informed treatment should be geared toward improving the quality of object relations and modifying overly punitive superego functions as reflected in intense self-criticism over rage at perceived abandonment by significant objects. Achievement of these goals is likely to require long-term psychotherapy and/or psychoanalysis.

The data of this study point to the importance of collaboration between psychoanalysts and psychodynamic researchers whose work is 
more empirical. The fact that strong support was found for an object relations and loss model of prediction of suicidal behavior, and that some support was obtained for the aggression hypothesis, indicates that psychoanalytic theories can be successfully subjected to empirical study and validation. In today's managed care climate, the relative absence of reproducible empirical data has been used to undermine a psychodynamic approach to the understanding of psychopathology. It is essential that such data be obtained.

\section{REFERENCES}

Apter, A., Plutchik, Savy, S., Korn, M., Brown, S., \& van Praag, H. (1989). Defense mechanisms in risk of suicide and risk of violence. American Journal of Psychiatry 146:1027-1031.

AsCH, S.S. (1980). Suicide and the hidden executioner. International Review of Psycho-Analysis 7:51-60.

BAUMEISTER, R.F. (1990). Suicide as escape from self. Psychological Review 97:90-113.

Beautrais, A.L., Joyce, P.R., Mulder, R.T., Fergusson, D.M., Devoll, B.J., \& NightingaLE, S.K. (1996). Prevalence and comorbidity of mental disorders in persons making serious suicide attempts: A case-control study. American Journal of Psychiatry 153:1009-1014.

BeCK, A.T., Kovacs, M., \& WeISSMAN, A. (1979). Assessment of suicidal intention: The scale for suicide ideation. Journal of Consulting and Clinical Psychology 47:343-352.

SCHUYLER, D., \& HeRMAN, I. (1974). Development of suicidal intent scales. In The Prediction of Suicide, ed. A.T. Beck, H.L.P. Resnik, \& D.J. Lettieri. Bowie, MD: Charles Press, pp. 45-56.

Steer, R.A., \& GaRBIN, M.G. (1988). Psychometric properties of the Beck Depression Inventory: Twenty-five years of evaluation. Clinical Psychology Review 8:77-100.

Ward, C.H., Mendelson, M., Mock, J.E., \& ERbaugh, J. (I96I). An inventory for measuring depression. Archives of General Psychiatry 4:561-571.

Bond, M. (1984/1986). Defense Style Questionnaire. In Empirical Studies of Ego Mechanisms of Defense, ed. G.E. Vaillant. Washington, DC: American Psychiatric Press.

Chance, S.E., Reviere, S.L., Rogers, J.H., James, M.E., Jessee, S., Rojas, L., HATCHER, C.A., \& KASLOW, N.J. (1996). An empirical study of the psychodynamics of suicide: A preliminary report. Depression 4:89-91.

COONERTY, S. (1986). An exploration of separation-individuation themes in borderline personality disorder. Journal of Personality Assessment 50:501-511. 
Cross, C.K., \& HiRSCHFIELD, R.M.A. (1 986). Psychosocial factors and suicidal behavior: Life events, early loss, and personality. Annals of New York Academy of Sciences 487:77-89.

DiAmOND, D., Kaslow, N., COONERTY, S., \& BlatT, S. (1990). Changes in separation-individuation and intersubjectivity in long-term treatment. Psychoanalytic Psychology 7:363-397.

EXNER, J.E. (1990). A Rorschach Workbook for the Comprehensive System. 3rd ed. Ashville, NC: Rorschach Workshops.

(1993). The Rorschach: A Comprehensive System: Volume 1. Basic Foundations. 3rd ed. New York: Wiley.

Fenichel, O. (1945). The Psychoanalytic Theory of Neurosis. New York: Norton.

FlanNery, R.B., \& PeRrY, J.C. (1990). Self-rated defense style, life stress, and health status: An empirical assessment. Psychosomatics 31:313-320.

FreUd, S. (1917). Mourning and melancholia, Standard Edition 14:243-258.

GioelLA, P. (1979). The shame-guilt scale. Unpublished manuscript, New York University.

HAIDER, I. (1968). Suicide attempts in children and adolescents. British Journal of Psychiatry 114:1113-1134.

Hendin, H. (199I). Psychodynamics of suicide, with particular reference to the young. American Journal of Psychiatry 148:1150-1158.

Jessee, S., Chance, S.E., D’Orio, B., \& Edelson, D. (1995/1996). Psychodynamic study of suicide attempts in patients with personality disorders. Depression 6:290-296.

Kernberg, O. (1975). Borderline Conditions and Pathological Narcissism. New York: Aronson.

- (1984). Severe Personality Disorders: Psychotherapeutic Strategies. New Haven: Yale University Press.

KLEIN, M. (1934). A contribution to the psychogenesis of manic-depressive stages. In Contributions to Psychoanalysis 1921-1945. London: Hogarth Press, pp. 228-310.

Knopf, I.J., Ballard, J.C., Fried, N.J., \& Spaeth, M.J. (1990) Self-targeted anger (STA) and depression. Paper presented to the Southeastern Psychological Association, Atlanta.

Kонuт, H. (1977). The Restoration of the Self. New York: International Universities Press.

Mahler, M., Pine, F., \& Bergman, A. (1975). The Psychological Birth of the Human Infant. New York. Basic Books.

Maltsberger, J.T., \& Buie, D.H. (1980). The devices of suicide: Revenge, riddance, and rebirth. International Review of Psycho-Analysis 7:61-72.

MARCUS, B. (1988). Cognitive regression and dynamic factors in suicide: An integrative approach. In Primitive Mental States and the Rorschach, ed. 
H.D. Lerner \& P.M. Lerner. Madison, CT: International Universities Press, pp. 155-174.

RADO, S. (195I). Psychodynamics of depression from the etiologic point of view. Psychosomatic Medicine 13:51-55.

ScHolz, J.A. (1973). Defense styles in suicide attempters. Journal of Consulting and Clinical Psychology 41:70-73.

SPITZer, R., Williams, J.B.W., GibBON, M., \& FirSt, M.B. (1990). Structured Clinical Interview for DSM-III-R Patient Edition (SCID-P, Version 1.0). Washington, DC: American Psychiatric Press. (1990b). Structured Clinical Interview for DSM-III-R Personality Disorders (SCID-II, Version 1.0). Washington, DC: American Psychiatric Press.

STERN, D.N. (1985). The Interpersonal World of the Infant: A View from Psychoanalysis and Developmental Psychology. New York: Basic Books.

Vaillant, G.E., Bond, M., \& Vaillant, C.O. (1986). An empirically validated hierarchy of defense mechanisms. Archives of General Psychiatry 43:786-794.

WASSERMAN, D. (1988). Separation: An important factor in suicidal actions. Crisis 9:49-63.

Westen, D., LOHR, N., SiLK, K.R., Gold, L., \& KeRBeR, K. (1990). Object relations and social cognition in borderlines, major depressives, and normals: A Thematic Apperception Test analysis. Psychological Assessment: A Journal of Consulting Clinical Psychology 2:355-264.

Williams, M.V., Parker, R.M., Baker, D.W., ParikH, N.S., Pitkin, K., Coates, W.C., \& NURSS, J.R. (1995). Inadequate functional health literacy among patients at two public hospitals. Journal of the American Medical Association 274:1677-1682.

WinnicotT, D.W. (1958). Collected Papers: Through Paediatrics to PsychoAnalysis. London: Tavistock Publications.

- (1960). The theory of the parent-infant relationship. In Maturational Processes and the Facilitating Environment. New York: Basic Books, 1965, pp. 37-55.

\author{
Nadine J. Kaslow \\ Emory University School of Medicine \\ Department of Psychiatry and Behavioral Sciences \\ Grady Health System \\ 80 Butler Street SE \\ Atlanta, GA 30335 \\ Fax: 404-616-324I \\ E-mail: Nkaslow@emory.edu
}

